\title{
A COVID-19 NO BRASIL E AS ATRIBUIÇÕES DOS AGENTES COMUNITÁRIOS DE SAÚDE: DESAFIOS E PROBLEMÁTICAS ENFRENTADOS NO CENÁRIO NACIONAL DE PANDEMIA
}

\author{
COVID-19 IN BRAZIL AND THE ASSIGNMENTS OF COMMUNITY HEALTH AGENTS: \\ CHALLENGES AND PROBLEMS FACED IN THE NATIONAL PANDEMIC SCENARIO
}

\author{
Rodrigo Nascimento Bentes \\ Especialista em Metodologia de Ensino de Geografia (UNIASSELVI) \\ Universidade do Estado do Pará - Campus Barcarena \\ rodrigogeouepa20@gmail.com
}

\begin{abstract}
RESUMO
Com o objetivo de pontuar as atribuições dos agentes comunitários de saúde, frente ao período de pandemia de Covid-19, compreendendo suas atribuições neste momento de necessidade nacional, a pesquisa, em caráter qualitativo, traz algumas contribuições com relatos de alguns profissionais sobre as constantes necessidades enfrentadas em seu cotidiano de trabalho, no que diz respeito às suas responsabilidades, orientados (ou não) pelos materiais formativos disponibilizados pelo Ministério da saúde, nas quais são incongruentes a realidade, contrapondo-se com as suas particularidades enfrentadas como a falta de equipamentos de proteção individual, falta de formação, recusa de visita domiciliares por parte dos atendidos e não valorização destes, sendo pontos que são problematizados em vários territórios encontrados no Brasil; é de fundamental necessidade o investimento em recursos para o Sistema Único de Saúde (SUS), priorizando a vida de cada indivíduo e contribuindo na qualidade de bem-estar de todos os que necessitam do sistema, pois o que se apresenta no cenário nacional atualmente, é o colapso que agrava ainda mais o acolhimento da maior parcela da sociedade que necessita ser amparados pelos serviços públicos de saúde.
\end{abstract}

Palavras-chaves: SUS. Covid-19. Agente comunitário de Saúde

\begin{abstract}
With the objective of punctuating the attributions of community health agents, in the face of the Covid-19 pandemic period, understanding their attributions in this moment of national need, the research, in qualitative character, brings some contributions with reports from some professionals about the constant needs faced in their daily work, with regard to their responsibilities, guided (or not) by the training materials provided by the Ministry of Health, in which the reality is incongruous, contrasting with their particularities faced such as the lack of equipment individual protection, lack of training, refusal of home visits on the part of those assisted and their lack of appreciation, being points that are problematized in several territories found in Brazil; investment in resources for the Unified Health System (SUS) is of fundamental necessity, prioritizing the life of each individual and contributing to the quality of well-being of all who need the system, because what is currently present in the national scenario, it is the collapse that further aggravates the reception of the largest part of society that needs to be supported by public health services.
\end{abstract}

Keywords: SUS. Covid-19. Community Health Agent.

\section{INTRODUÇÃO}

Com o atual cenário mundial de contaminação desde os últimos meses de 2019, enfrenta-se por conta do Vírus SARS-CoV-2, que causa a Covid-19, uma pandemia na qual trouxe muitos agravantes a saúde, levando aos casos mais sérios a evolução ao óbito de diversas pessoas, independente de idade, classe social, sexo e origem, manifestando grandes problemáticas aos serviços de saúde em todos os países de forma preocupante.

Recebido em: 02/05/2020

Aceito para publicação em: 04/06/2020. 
Cada nação busca atender sua população com ações de controle e combate a não contaminação de uma grande parcela populacional ao mesmo tempo, pois isso acarretaria na grande procura aos hospitais de atendimento e pouca demanda e, assim a não disposição de materiais necessários para o tratamento, sucumbindo as áreas hospitalares, impossibilitando a ajuda a promoção à saúde a todos os que procuram destes serviços.

No Brasil, estas medidas de prevenção, também não são diferentes, e por ter à disposição o Sistema Único de Saúde (SUS) também orienta de forma continua a população a opção de isolamento social para as pessoas não contaminadas com o vírus, uma vez que em lógica, diminui a quantidade de casos para não sobrecarregar as unidades de saúdes, Unidades de Pronto Atendimento, entre outras modalidades de serviço ofertado pelo sistema, para assim não sobrecarregar com número de casos suspeitos ou contaminados estas unidades.

Dentre os profissionais de saúde nos quais hoje fazem parte do "pelotão de frente" para enfrentar, conduzir, tratar e prevenir, ressalta-se nesta modéstia pesquisa, o Agente comunitário de saúde, que muitas vezes não recebe o devido reconhecimento e que cotidianamente está dentro do território domiciliar das famílias e que são porta-vozes dos principais condicionalidades individuais e coletivos de cada domicilio visitado para as devidas ações dentro do sistema de atenção básica de saúde no País.

A presente pesquisa frisa pontuar algumas as atribuições recomendadas pelo Ministério da Saúde (MS) para a adequação dos agentes comunitários de saúde frente a atual situação epidemiológica referente aos casos de Covid-19, e junto a estas recomendações pontuar mediante a própria realidade enfrentadas pelos trabalhadores, verificar se estas orientações correspondem à realidade enfrentadas pelos trabalhadores no cotidiano de suas visitas domiciliares.

\section{CARACTERISTICAS GERAIS SOBRE A INFECÇÃO DO VIRUS DA COVID-19}

A covid-19, segundo dados da Organização Mundial da Saúde (OMS), foi diagnosticado pela primeira vez, em Wuhan na china em meados do mês de novembro de 2019. A partir desta descoberta foi identificado como um vírus e sendo atribuído aos diversos casos de surtos de doenças respiratórias na região da Ásia. A partir disto, o mundo começou a ficar alerta sobre o vírus e foram gradativamente desenvolvendo seus planos de ação para conter uma pandemia que poderia pôr o fim a vida de centenas de milhares de pessoas, por conta desta contaminação.

No dia 22 de janeiro de 2020, foi ativado o Centro de operações de emergências em saúde pública para o novo coronavírus, na qual foi incumbida de desenvolver estratégias para responder as possíveis problemáticas que adviriam das consequências ocasionadas pela contaminação do Covid-19 no país.

O Brasil dispõe de um Plano Nacional de respostas ás emergências em saúde pública, o que consequentemente, fez com que após dado início, fossem desenvolvidos desde 2005 pelo SUS, a missão de aprimorar as ações de voltadas a problemáticas quanto ao sistema respiratório, para poder assim, identificar, monitorar, tratar e reestabelecer a saúde daqueles que forem acometidos por tal situação. (BRASIL 2020a, p.5)

A partir disto, nesta atual fase do cenário epidemiológico que o Brasil enfrenta, há a ocorrência de constantes adaptações nos protocolos por meio dos avanços científicos e dados atualizados por meio da OMS e órgãos de saúde que buscam evidenciar medidas preventivas e planos de vigilância para que os Estados e municípios brasileiros, que possuem planos próprios a sua realidade, possam realizar ações contra esses eventos em massa como ocorrido, mundialmente.

Partindo desta perspectiva, cabe aos Estados e municípios, descartar primeiramente todos os quadros de doenças respiratórias para assim poder agir em caso de confirmação para Covid-19, onde para o SUS, por possuir a capacidade segundo Brasil (2020a, p.6) e experiência, pode ter uma contar com uma contrapartida

Quanto a descrição do Covid-19, esta causa infecções respiratórias e intestinais nos seres humanos e animais, tendo como sintomas, desde um resfriado comum, até infecções de alto risco, sendo de grande periculosidade em pacientes com doenças crônicas como idosos e crianças, pessoas com comorbidades e imunodeprimidos. Através dos dois tipos de espécies virais altamente patogênicas e provenientes de animais (SARS e MERS) nos quais foram responsáveis pelas síndromes respiratórias agudas. (BRASIL, 2020a, P.9)

Sobre o agente etimológico, segundo Brasil (2020a, p.9) os vírus da SARS-CoV e MERS-CoV e (2019$\mathrm{nCoV}$ ), (esta última segundo a literatura do ministério da saúde, também titulado para o novo 
coronavírus), são subfamiliares e betacoronavírus que são transmitidos para mamíferos e causam infeções no trato respiratório e infecção intestinal.

Sua forma de transmissão e de reservatório, a mesma se deram na região da China, na província de Wuhan, onde através de comercialização de frutos do mar e animais vivos, possivelmente sendo os principiais disseminadores desta doença para humanos, e depois entre os humanos.

Segundo Brasil (2020a, p.10), logo após os veículos de informação divulgaram que as autoridades chinesas relataram o contagio entre pessoas e que o vírus já se espalhara pelos países como EUA, Alemanha, Japão e Vietnã, e que estavam também sendo transmitidos pelos hospitais e outros pontos de atendimento médico, como relatados também pelos franceses em pesquisas.

A disseminação se deu principalmente por gotículas de fluidos, expelidas pelas vias respiratórias produzidas no espirro e tosse da pessoa, da mesma forma como se contamina nos casos de influenza, sendo mesmo de fácil transmissão e contagio, sem as devidas orientações de higiene e cuidado.

O Ministério da saúde brasileiro, descreve que o período de incubação e pela infecção é de 5.2 dias e pode ter intervalo até o decimo segundo dia, levando em consideração as pessoas não expostas na feira de Wuhan, mas sim pelo contato comunitário, não necessariamente pelo o animal contaminado, mas sim, pela ocorrência de pessoas entre si.

A transmissão por SARS-CoV desenvolve-se em média de 7 dias após o início dos sintomas, porém novos estudos informam que a transmissão da Covid-19 ocorre sem ao menos apresentar sinal e sintoma, o que é alguns casos a contagem de dias e manifestações de sintomas sugerem que a transmissão possa ocorrer, mesmo sem o aparecimento de alguma reação no organismo.

Segundo Brasil (2020a, p.11) a Covid-19 ainda precisa passar por mais investigações não está estabelecido completamente o espectro, necessitando de mais investigações e tempo para caracterização da doença. Segundo os dados mais atuais, os sinais e sintomas clínicos referidos são principalmente respiratórios. O paciente pode apresentar febre, tosse e dificuldade para respirar.

Após avaliação realizada com mais de 99 pacientes ainda na China, em Wuhan, 99 pessoas contaminadas de 2019-nCoV apresentavam pneumonia e segundo Brasil (2020a, p.11) além destas reações apresentam em proporção outros sintomas nas quais são descritas pelo relatório em Wuhan:

(...) no hospital de Wuhan, aponta-se maior taxa de hospitalização em maiores de 50 anos, sexo masculino. Os principais sintomas foram febre $(83 \%)$, tosse $(82 \%)$, falta de $\operatorname{ar}(31 \%)$, dor muscular $(11 \%)$, confusão $(9 \%)$, dor de cabeça $(8 \%)$, dor de garganta $(5 \%)$, rinorréia $(4 \%)$, dor no peito $(2 \%)$, diarréia $(2 \%)$ e náusea e vômito $(1 \%)$. Segundo exames de imagem, 74 pacientes (75\%) apresentaram pneumonia bilateral, 14 pacientes $(14 \%)$ apresentaram manchas múltiplas e opacidade em vidro fosco e 1 paciente $(1 \%)$ evoluiu com pneumotórax. Também houve registros de linfopenia em outro estudo realizado com 41 pacientes diagnosticados com 2019-nCoV. Complicações. As complicações mais comuns são Síndrome Respiratória Aguda Grave - SRAG (17-29\%), lesão cardíaca aguda (12\%) e infecção secundária (10\%). A letalidade entre os pacientes hospitalizados variou entre $11 \%$ e $15 \%$.

Atualmente, em meados de maio de 2020, nas quais já se passaram 7 meses desde o primeiro caso confirmado de Covid-19, no Brasil, segundo o site de notícias G1, são aproximadamente 88 mil casos espalhados no Estados do País, onde estes dados são fornecidos pelas secretarias de saúde, o que expressa a grande quantidade de pessoas infectadas e que gradativamente apresentam os sintomas, que forem descritos desde a China, através dos relatórios desenvolvidos pelo Ministério da Saúde.

\section{ATRIBUIÇÕES REALIZADAS PELOS AGENTES COMUNITÁRIOS DE SAÚDE PROPOSTAS NO ATUAL CONTEXTO DE COVID-19}

$\mathrm{Na}$ atenção básica, o Agente comunitário de saúde (ACS) contribui no processo de propagação de cuidados de saúde para população, atuando ativamente como representante dos Sistema Único de Saúde, uma vez que contribui para a promoção da atenção básica seja mantida em territórios nas quais muitas vezes não tem as devidas referências à saúde.

Neste momento, onde a pandemia de Covid-19 está crescendo, as pessoas encontram-se grande parte em isolamento social, ou até mesmo realizando suas funções fora de seus domicílios, então mediante a isto, foi desenvolvido uma série de medidas para que este profissional, propague neste período vivido.

Segundo Brasil (2020b, p.3) dentro das funções atribuídas nesta realidade enfrentada aos ACS's, estão as seguintes medidas são pontuadas: 
- auxiliar a equipe na identificação de casos suspeitos.

- orientar durante as visitas domiciliares que crianças menores de 5 anos com sinais e sintomas respiratórios devem procurar a unidade de saúde. Caso o município e/ou a unidade apresentem fluxo próprios, os mesmos devem ser seguidos.

- orientar durante as visitas domiciliares que pessoas com 60 anos ou mais com sinais e sintomas respiratórios devem entrar em contato com a unidade de saúde. Caso o município e/ou a unidade apresentem fluxo próprios, os mesmos devem ser seguidos. - auxiliar no atendimento através do FAST-TRACK COVID-19 (...) na identificação de pacientes sintomáticos, tomando os devidos cuidados de proteção e isolamento.

- auxiliar a equipe no monitoramento dos casos suspeitos e confirmados.

- realizar busca ativa de novos casos suspeitos de síndrome gripal na comunidade.

- realizar busca ativa quando solicitado. Principalmente em casos de pacientes que se enquadram no grupo de risco (gestante, pessoas com doenças crônicas, puérperas e idosos) e não compareceram a unidade de saúde para a realizar a vacina contra influenza.

- organizar o fluxo de acolhimento de modo a evitar aglomeração de grupos com mais de 10 pessoas e, preferencialmente em ambientes arejados.

- auxiliar as atividades de campanha de vacinação de modo a preservar o trânsito entre pacientes que estejam na unidade por conta de complicações relacionadas ao covid-19, priorizar os idosos.

- realizar atividades educativas na unidade enquanto os pacientes aguardam atendimento. (BRASIL, 2020b, p.3)

Incluindo estas recomendações de acordo com o ministério da saúde, o profissional deve auxiliar também sua unidade de saúde quando necessário de acordo com o fluxo de seus estabelecimentos, onde frisa-se as recomendações de segurança para a melhor atenção e cuidado junto a demanda que necessita no momento de orientação ou consulta clinica avaliativa.

Quanto as visitas domiciliares, que são de fundamental importância no dia a dia do ACS, paras os casos ativos de suspeita, as visitas devem ser feitas com certas restrições para pode manter a segurança devida e respaldo dos pacientes que estão mantendo o isolamento domiciliar. O ministério de saúde, faz as seguintes recomendações em relação as essas visitas:

- não realizar atividades dentro domicílio. A visita estará limitada apenas na área peri domiciliar (frente, lados e fundo do quintal ou terreno).

- priorizar visita aos pacientes de risco (pessoas com 60 anos ou mais ou com doenças crônicas não transmissíveis como diabetes, hipertensão, doença cardíaca, doença renal crônica, asma, DPOC, doença cardíaca, imunossuprimidos, entre outras). Por serem grupo de risco, são os que precisam de mais cuidado também.

- manter distanciamento do paciente de no mínimo 1 metro, não havendo possibilidade de distanciamento, utilizar máscara cirúrgica.

- higienizar as mãos com álcool em gel.

- nos casos de visita às pessoas com suspeitas de Covid-19, sempre utilizar máscara cirúrgica e garantir uso de EPI apropriado. Agente Comunitário de Saúde (ACS) que apresentar febre e qualquer sintoma respiratório (tosse, coriza, dor de garganta, falta de ar, etc), deve permanecer em isolamento domiciliar conforme orientação do médico e/ou enfermeiro (BRASIL 2020b, p.4).

As recomendações dadas aos trabalhadores com mais de sessenta anos e eu apresentam doenças crônicas como doentes cardíacos, doentes respiratórios crônicos, doentes renais em estágio avançados e em diálise, imunossuprimidos e diabetes, precisa trabalhar na área administrativa das unidades de saúde, que não necessariamente precise realizar o atendimento em público.

Quanto ao processo de identificação de casos suspeitos dos casos de síndrome gripal e de Covid-19, os agentes de saúde farão a busca ativa dos pacientes com essas sintomatologias e fazer as perguntas chaves sobre quais reações o mesmo veio a desenvolver, o contato com possíveis pessoas contaminadas e descreve-las tais como os sintomas de tosse, dor de garganta, desconforto ou esforço respiratório com ou sem e febre, averiguado nas visitas e nos casos notificados nas unidades de saúde.

O ministério da saúde orienta que deve ser fornecido a máscara cirúrgica para os pacientes que apresenta essas manifestações clinicas de sintomas respiratórios, que haja higienização das mãos e recomendação de não tocar sem os devidos cuidados de higiene, o rosto, e em áreas superficiais onde tenha contato direto com outras pessoas, tendo prioridade nos casos confirmados em visita domiciliar de Pessoas acima de 60 anos, imunossuprimidos (HIV+, transplantados, etc), pacientes com doenças crônicas, gestantes e puérperas (até 45 dias após o parto). (BRASIL, 2020b p.4). 
Como reforço o ministério da saúde segundo Brasil (2020b p.5) recomenda que o ACS precisa orientar que o processo de isolamento domiciliar é necessária, uma vez que contribuem na não propagação em massa desse vírus, que para aqueles com síndrome gripal, a permanecia na casa por aproximadamente 14 dias são necessárias e que haverá as visitas de acompanhamento de quadro de saúde pessoal a cada 48 horas pelos mesmos, de acordo com as orientações dos médicos e enfermeiros que os acompanharam no processo inicial de atendimento, pelo telefone. Assim em caso de melhora ou piora do caso clinico, a equipe de saúde poderá conduzir e acionar os próximos níveis de atendimento para acompanhamento dos pacientes, principalmente nos casos de manifestações de falta de ar novos sintomas clínicos.

\section{DISCURSOS SOBRE AS PROBLEMÁTICAS ENFRENTADOS NO CENÁRIO NACIONAL DE PANDEMIA PELO AGENTE COMUNITARIO DE SAÚDE}

Neste presente tópico, busca-se ressaltar algumas contribuições de ACS's, e por vivência própria do autor, pois realiza a função de agente comunitário a 8 anos, na qual motivou a construção desta temática, abordando as problemáticas enfrentadas no trabalho, também nestes tempos de pandemia do Covid-19.

Em consideração aos materiais dispostos pelo MS, tanto os de cunho técnico, quando os direcionados para os profissionais de saúde, em particular a área referenciada dos agentes de saúde, as considerações feitas nos mesmos são de grande contribuição para a formação e entendimento das principais posições a serem tomadas frente ao combate da não contaminação de Covid-19, porém, em dadas circunstâncias, tais materiais desenvolvidos não refletem diretamente a realidade dos diversos territórios nas quais representam o Brasil, uma vez que no atual cenário nacional, o SUS, encontra-se em colapso por falta de recursos, não podendo proceder ao grande número de doentes que encontramse infectados, além de outras problemáticas de saúde já existentes, que demandam atendimento e cuidados no processo saúde-doença.

Os comentários de tais realidades, expressam de forma verossímil as condições nas quais os agentes comunitários enfrentam em circunstancias do trabalho, e o mesmo é evidenciado aqui, contrariando tais recomendações dados no documento desenvolvidos ministério da saúde. Os Estados e municípios da federação buscam de todas as formas possíveis, investimentos nas quais possam suprir com suas devidas necessidades, no entanto, muitos sem grande sucesso vem conseguindo verba orçamentária, por conta da necessidade que é enfrentada por todos os Estados brasileiros.

Pontua-se mais uma vez, a oportunidade de expor, frente ao sucateamento que o sistema de saúde pública brasileira vem enfrentando, de que a valorização das necessidades de todas as pessoas envolvidas no processo promoção a saúde à vida humana, precisam de subsídios para desempenhar suas funções, com qualidade de materiais hospitalares, valorização salarial e demandando de estrutura física para atendimento, para prestar um serviço com integridade e humanização.

As transcrições dos argumentos realizadas aqui, pelos profissionais de saúde refletem uma necessidade que é vista em quase todos os Estados do país, onde, os municípios de recorte na qual foram coletadas tais informações, foram os de Belém e Barcarena, municípios do Estado do Pará; Seringal Curitiba, no Acre; Martinho campos e Dom Caváti em Minas gerais; Xique-Xique, na Bahia; Amparo, São Paulo.

Através dos comentários dos Agentes comunitários de saúde nas quais desempenham suas funções em um ambiente de difícil realidade, comparadas as atribuições requisitadas pelo MS, nos seus materiais formativos para esta categoria de trabalho, apresentam um contexto diferente do orientado, demostrando as contrariedades do SUS, da gestão que coordenam cada programa de ACS's, e falta de valorização desta classe de trabalhadores que arriscam suas vidas ao não está devidamente orientado, ou com falta de equipamento de proteção individuais (EPI's), mal remunerados e prestando serviços em áreas insalubres.

A categorização das respostas dadas pelos profissionais de saúde, serão enquadradas junto aos recortes das orientações dadas pelo material formativo do MS utilizado nesta pesquisa; o processo de categorização de respostas, se dá segundo a análise de Bardin (2009, p.121), que caracteriza esta forma de ação como uma técnica coerente usada para à análise de conteúdo dado pela utilização de uma questão levantada, ou questionário e, a categorização de informações subsidiadas para interpretação relevante segundo consta o quadro a seguir, que agrupa as recomendações dadas por Brasil (2020b) e as relaciona a realidade enfrentada pelo ACS, de forma pontuar de fato a real condição na qual são postos no cotidiano de pandemia no país. 
Quadro1- analise de propostas feitas pelo ministério da saúde e realidade enfrentada pelos ACS's.

\begin{tabular}{|c|c|}
\hline $\begin{array}{c}\text { Atribuições dos ACS's frente a situação de } \\
\text { pandemia de Covid- } 19\end{array}$ & $\begin{array}{l}\text { Dificuldades e problemáticas enfrentadas pelos } \\
\text { profissionais no cotidiano de visitas domiciliares }\end{array}$ \\
\hline $\begin{array}{l}\text { (...) auxiliar no atendimento através do FAST-TRACK } \\
\text { COVID-19 (...) na identificação de pacientes } \\
\text { sintomáticos, tomando os devidos cuidados de } \\
\text { proteção e isolamento. (BRASIL, 2020c, p. 3) }\end{array}$ & $\begin{array}{c}\text { "Não recebemos formação para enfrentar esse } \\
\text { momento em que estamos vivendo, muitas vezes } \\
\text { vamos somente com algumas orientações feitas pela } \\
\text { enfermeira para a área". (E.S) }\end{array}$ \\
\hline $\begin{array}{l}\text { (...) realizar busca ativa quando solicitado. } \\
\text { Principalmente em casos de pacientes que se } \\
\text { enquadram no grupo de risco (gestante, pessoas com } \\
\text { doenças crônicas, puérperas e idosos) e não } \\
\text { compareceram a unidade de saúde para a realizar a } \\
\text { vacina contra influenza. (BRASIL, 2020c, p. 3) } \\
\text { (...) auxiliar as atividades de campanha de vacinação } \\
\text { de modo a preservar o trânsito entre pacientes que } \\
\text { estejam na unidade por conta de complicações } \\
\text { relacionadas ao covid-19, priorizar os idosos. } \\
\text { (BRASIL, 2020c, p. 3) }\end{array}$ & $\begin{array}{c}\text { "As vacinas de influenza estão em falta aqui no } \\
\text { município, e o pouco que temos não deram para } \\
\text { todos, muitos dos nossos pacientes idosos estão sem } \\
\text { vacina e reclamam com razão". (M.I) } \\
\text { "Não conseguir vacinar nem todos meus atendidos } \\
\text { idosos, por que não deu, a quantidade está sendo } \\
\text { insuficiente". (G.B) }\end{array}$ \\
\hline $\begin{array}{l}\text { (...) não realizar atividades dentro domicílio. A visita } \\
\text { estará limitada apenas na área peri domiciliar (frente, } \\
\text { lados e fundo do quintal ou terreno). (BRASIL, 2020c, } \\
\text { p. 3) }\end{array}$ & $\begin{array}{l}\text { "Várias pessoas estão rejeitando nossas visitas, } \\
\text { acham que estamos transmitindo o vírus, por termos } \\
\text { contato com pacientes com suspeita de coronavírus". } \\
\text { (R.B) }\end{array}$ \\
\hline $\begin{array}{l}\text { (...) manter distanciamento do paciente de no mínimo } \\
1 \text { metro, não havendo possibilidade de } \\
\text { distanciamento, utilizar máscara cirúrgica. (BRASIL, } \\
2020 \text { c, p. } 4 \text { ) }\end{array}$ & $\begin{array}{c}\text { "Gostaria de saber, se não passarem mascaras para } \\
\text { nós, podemos recusar a visitar? Estamos tendo } \\
\text { racionamento de EPI e não tem o suficiente para } \\
\text { todos". (S.A) } \\
\text { "As maiores dificuldades são algumas pessoas que } \\
\text { não querem obedecer às normas de distanciamento, } \\
\text { quando vamos orientar se revoltam contra nós, } \\
\text { também precisamos de óculos para o trabalho, ainda } \\
\text { não chegou para nós(...)". (M.A) } \\
\text { "Não estamos autorizadas a ir para rua fazer VD } \\
\text { (visita domiciliar), mas, vamos revezar no polo de } \\
\text { covid-19" (M.R.R) }\end{array}$ \\
\hline $\begin{array}{c}\text { (...) higienizar as mãos com álcool em gel. } \\
\text { (BRASIL, 2020c, p. 4) } \\
\text { Obs.: Comentários também sobre Equipamentos de } \\
\text { proteção individual" }\end{array}$ & $\begin{array}{l}\text { “Já tentei pegar álcool em gel e mascaras e na minha } \\
\text { UBS não tem”. (J.C) } \\
\text { "Falta de EPI, muitas cidades sem apoio também, (...) } \\
\text { nunca ouvi falar lembrar dos ACS estão nessa luta da } \\
\text { pandemia, os que dizem que nos representam } \\
\text { sumiram". (S.S.M) } \\
\text { "Aqui exigem o uniforme, mas não o fornecem, todos } \\
\text { tivemos que pagar caro para fazer, a tal } \\
\text { insalubridades também não temos..." (C.E) } \\
\text { "A situação aqui é difícil, mas continuamos recebendo } \\
\text { apenas uma máscara para três meses de uso (...)" } \\
\text { (C.X.S) } \\
\text { “(...) descaso quanto aos equipamentos de proteção" } \\
\text { (L.S) }\end{array}$ \\
\hline
\end{tabular}

Fonte: autoral (2020) 
O que se observa nestas colocações de alguns trabalhadores de saúde, é a realidade na qual, a falta de material, em alguns casos, de formação e até mesmo falta de condicionantes para o trabalho realizado com diversas dificuldades, são ocorrentes no cotidiano no sistema público de saúde e que precisam ser revistas pelos governos da esfera Federal, Estadual e municipal, frente aos problemas que ainda apodem ocorrer no país, por conta dos número de casos que vem surgindo diariamente, e não cessa e crescer.

Neste momento, os serviços já existentes no sistema de saúde, que outrora eram destinados para diversas demandas de tratamento, estão "em segundo plano", uma vez que se prioriza os atendimentos de caso de coronavírus e que agora são tolamente destinados ao serviço de atendimentos aos pacientes contaminados pela Covid-19. É preocupante este cenário atual na qual vive-se nos dias atuais no Brasil, visto aos investimentos que são necessários no serviço de saúde nas três esferas territoriais, há cortes de verbas significativos que vem ocorrendo constantemente no SUS que poderiam contribuir no fortalecimento dos níveis primário, secundário e terciário de saúde, como os já ocorrido em privação de investimentos PEC $241^{2}$.

A falta de materiais, como álcool em gel e mascaras, são uma realidade real, e que vem prejudicando e muito o serviço de visita domiciliares, visto a necessidade de estar pronto para contribui com a demanda na qual necessidade de uma orientação ou até mesmo uma atenção nas visitas domiciliares, e a duração destes itens de produção tem um tempo de validade e uso muito pequeno.

A informação é muito necessária nestes tempo de recolhimento social e de enfretamento deste viris no país e no mundo, pois cada vez mais as Fake News, estão distorcendo informações que são preciosas para um melhor controle e formação comunitário, não gerando aglomerações e aumentos os casos já existentes e que não para de crescer a cada dia. Por esta falta de conhecimento ou até mesmo o conhecimento advindo de fontes erradas de noticiais e comunicação, acontece frequentemente a rejeição de visitas em domicílios por parte dos pacientes visitante aos ACS.

\section{PARA NÃO CONCLUIR}

Com o objetivo de evidenciar alguns pontos de incongruências nos materiais desenvolvidos pelo Ministério da saúde, o objetivo da pesquisa em suma, foi pontuar algumas das situações vividas pelos profissionais que podem ser revertidas, uma vez que investimentos sejam realizados de forma coerente na saúde pública do país. Precisa-se rever conceitos e posturas frente ao grande número de óbitos que já em 7 meses no mundo, e 5 meses no Brasil, vem matando pessoas de todos os tipos de classes sociais, etnias, raça, gêneros, ceifando a vida de maneira brusca e de maneira silenciosas.

A priori tal pesquisa não foi desenvolvida para fins sensacionalistas, ou para denigrir a imagem de nenhuma personalidade política atual que infelizmente não zela pelo seu governo e muito menos não sabe liderar de fato uma nação, como o Brasil, cheio de pluralidades, de vidas, de sonhos; o mesmo tem como oportunidade mostrar mesmo que em breves relatos, situações que podem também não contribuir para a vida das pessoas que almejam ser atendidos pelo sistema de saúde pública e que infelizmente, faz parte dos dados exibidos de óbitos em todo o país.

$\mathrm{Na}$ verdade, frisa-se valorizar aqui o papel do agente comunitário de saúde, no meio destes dias tão difíceis e inseguros, que estão ocorrendo nas visitas domiciliares, nas mais diversas realidades territoriais vividas, estes profissionais são contribuintes para o acesso aos serviços de saúde e, lutam arduamente contribuindo na promoção de melhores condições de bem-estar de dezenas de milhares de vidas que constitui o imenso território brasileiro.

Pontua-se que o sistema de saúde vem constantemente recebendo uma demanda maior de pacientes, e atualmente já se encontra em estado de calamidade e colapso em alguns Estados e municípios do país, porém, se políticas públicas e investimentos consideráveis for redistribuídos para os setores de atendimento do SUS, com certeza minimizara o avanço do número de mortos que estão sendo constantes e progressivos; os investimentos em ciência em pesquisa devem ser retomados e valorizados, uma que antes, pelo atual governo, são considerados de "coisa desnecessária que só gasta dinheiro público" e lugar de "gente de esquerda", não observando a importância para o desenvolvimento de vacinas e medidas técnicas para valorização do meio cientifico, valorizando ainda

\footnotetext{
${ }^{2}$ A Emenda Constitucional do Teto dos Gastos Públicos alterou a Constituição brasileira de 1988 para instituir o Novo Regime Fiscal. Durante o processo legislativo recebeu diversas denominações: PEC do Teto, PEC 241 na Câmara dos Deputados e PEC 55 no Senado Federal.
} 
a expectativa de cura deste vírus que até agora não foi descoberta no mundo. Espera-se que essa condição esteja em outro panorama em breve e a cura seja acessível a todos.

\section{REFERÊNCIAS}

BARDIN, L. Análise de conteúdo. Lisboa, Portugal; Edições 70, LDA, 2009.

G1. Casos de coronavírus e número de mortes no Brasil em $1^{\circ}$ de maio. Disponível em: https:<//g1.globo.com/bemestar/coronavirus/noticia/2020/05/01/casos-de-coronavirus-e-numero-demortes-no-brasil-em-1o-de-maio.ghtml>. Acesso em: 01 de maio. 2020.

BRASIL. Ministério da saúde. Secretaria de vigilância em saúde. Protocolo de tratamento do novo coronavírus (2019-nCoV). Brasília. 2020a. disponível em: https:<//portal.fiocruz.br/noticia/ministerioda-saude-lanca-protocolo-de-tratamento-do-covid-19>.pdf. Acesso em: Abr.2020.pdf

Ministério da Saúde. Secretaria de Vigilância em Saúde. Departamento de Vigilância das Doenças Transmissíveis. Recomendações para adequação das ações dos agentes comunitários de saúde frente à atual situação epidemiológica referente ao covid-19. Brasília. 2020b. Disponível em: http:<//www.cosemssp.org.br/noticias/recomendacoes-para-adequacao-das-acoes-dos-agentescomunitarios-de-saude-frente-a-atual-situacao-epidemiologica-referente-ao-covid-19/>. Acesso em: Maio.2020.pdf 